\title{
Percepções de homens com transtornos mentais sobre risco e autocuidado face às infecções sexualmente transmissiveis'
}

\author{
Perception of men with mental disorders about risk and \\ self-care for sexually transmitted diseases
}

\author{
Jaqueline Almeida Guimarães Barbosa \\ Doutora em Enfermagem. Membro do Grupo de Pesquisa em Epide- \\ miologia e Avaliação em Saúde e Docente do Centro Universitário \\ Metodista Izabela Hendrix. \\ Endereço: Rua Antônio de Albuquerque, 1313/60I, Bairro de Lour- \\ des, CEP 30112-olı, Belo Horizonte, MG, Brasil. \\ E-mail: jaquelineœtask.com.br \\ Maria Imaculada de Fátima Freitas \\ Doutora em Ciências da Educação. Membro do Grupo de Pesquisa \\ em Epidemiologia e Avaliação em Saúde, Professora titular da \\ Escola de Enfermagem da Universidade Federal de Minas Gerais. \\ Endereço: Escola de Enfermagem da UFMG, Av. Alfredo Balena, 190, \\ Bairro Santa Efigênia, CEP 30130-100, Belo Horizonte, MG, Brasil. \\ E-mail: peninhabhळyahoo.com.br \\ I Este trabalho foi conduzido pela Universidade Federal de Minas \\ Gerais (UFMG) com o apoio técnico e financeiro do Ministério da \\ Saúde/Secretaria de Vigilância em Saúde/Departamento de DST, \\ Aids e Hepatites Virais, por meio do Projeto de Cooperação Técnica \\ 914/BRA/ıIo entre o governo brasileiro e a Organização das Nações \\ Unidas para a Educação, a Ciência e a Cultura (Unesco).
}

\section{Resumo}

Estudos recentes mostraram altas taxas de infecções sexualmente transmissíveis (IST) entre pessoas com transtornos mentais no Brasil. Visando contribuir para avanços nas ações de prevenção junto a essa população, neste trabalho são analisadas as percepções de homens com transtornos mentais sobre risco e autocuidado face às IST. Entrevistas abertas e em profundidade com questões sobre autocuidado em saúde sexual foram realizadas com 22 homens com transtornos mentais. Os dados das entrevistas foram analisados com base na análise estrutural de narração. Os resultados mostraram que os entrevistados pouco conhecem sobre as IST. Apesar de reconhecerem a existência de risco nas relações sexuais, o uso de preservativo é raro. 0 principal aspecto dificultador do uso decorreu da representação de que pessoas aparentemente sadias não representam riscos. Entre os que fizeram uso do preservativo, essa conduta esteve motivada pela proximidade de experiências de uma IST contraída. Entretanto, o uso foi prejudicado por acharem que o preservativo compromete o prazer e também pelo uso de álcool e drogas. Alguns não encontram sentido em se autocuidar, o que se mostrou atrelado ao contexto de exclusão social. Houve ainda situações em que se preferiu correr o risco de se infectar. Faz-se urgente promover saúde sexual para essa população, considerando os aspectos psicossociais envolvidos no autocuidado.

Palavras-chave: Doenças Sexualmente Transmissíveis; Pessoas Mentalmente Doentes; Autocuidado. 


\section{Abstract}

Recent studies have shown high rates of sexually transmitted infections (STI) among people with mental disorders in Brazil. In order to contribute to the enhancement of preventive actions for this population, this work analyzed the perceptions of men with mental disorders of the risk and self-care regarding STIs. Open in-depth interviews on self-care and sexual health issues were held with 22 men with mental disorders. Data were examined based on the structural analysis of narration. The results showed that respondents know little about the STIs. Despite recognizing the existence of risk in sexual relations, the use of condoms was rare. The main obstacle to their use was their representation that people who appear healthy do not present risks. Among those who did use condoms, this conduct was motivated by the proximity of experiences in which STIs were contracted. However, this use was hampered by their belief that the condom diminishes the pleasure and also by the use of alcohol and drugs. Some do not find meaning in self-care, a feeling associated to the context of social exclusion. There were also situations in which the men preferred to run the risk of becoming infected. The promotion of sexual health in this population is urgent, one able to consider the psychosocial aspects involved in self-care.

Keywords: Sexually Transmitted Diseases; Mentally-ill People; Self-care.

\section{Introdução}

Este artigo analisa as particularidades da vulnerabilidade masculina de homens com transtornos mentais severos e persistentes às infecções sexualmente transmissíveis (IST), tendo em vista que esse grupo apresentou taxas preocupantes desses agravos - a taxa de infecção pelo HIV foi superior à da população em geral (Guimarães e col., 2009). 0 termo vulnerabilidade foi introduzido na área da saúde em 1992, quando se passou a considerar aspectos sociais e culturais envolvidos na problemática da aids (Mann e col., 1992). Desde então a exposição a riscos face aos agravos transmissíveis deixou de ser vista apenas como uma conduta racional de responsabilidade individual, pela qual os indivíduos eram culpados. As atitudes de exposição ou cuidado passaram a ser entendidas como o conjunto integrado dos aspectos sociais, programáticos e individuais que colocam os sujeitos em relação com o problema e os recursos para seu enfrentamento (Ayres e col., 1999). Nesse estudo, o enfoque será o da vulnerabilidade social decorrente do repertório de crenças e valores acerca dos riscos face às IST, o que se pressupõe ter íntima relação com o autocuidado para a saúde sexual.

Pessoas com transtornos mentais caracterizam-se por formar um grupo social que sofre com o preconceito e a exclusão social, ficando privado do acesso à educação e à renda. Essas pessoas são ainda vistas como assexuadas ou possuidoras de uma sexualidade que deva ser reprimida (Brito e Oliveira, 2009), sendo escassas as ações de promoção da saúde sexual voltadas para elas nos serviços de saúde. Em estudo realizado por Melo e colaboradores (2007), do qual participaram 27 serviços públicos de atenção em saúde mental no Brasil, encontrou-se que em apenas $26,9 \%$ havia algum programa de educação sexual. Além disso, essas ações, quando realizadas, têm caráter apenas informativo, abordando a temática de forma prescritiva e generalizada, ignorando os sentidos particulares que cada pessoa atribui à vivência da sexualidade e aos riscos e condutas de autocuidado para a saúde sexual, bem como aos seus contextos de vida, salvo exceções (Brasil, 2008).

Soma-se a isso o fato de que raros são os estudos de cunho qualitativo com foco na prevenção das IST 
realizados com essa população no Brasil. Os existentes mostram que essas pessoas têm conhecimentos limitados sobre as IST, e mesmo conhecendo o preservativo o seu uso não é assegurado. Eles mostram ainda que para alguns exporem-se ao risco de contrair IST é algo indiferente, mesmo sendo marcante a representação da incurabilidade da infecção pelo HIV. Os trabalhos mostram também que muitos não se veem em risco e enfrentam dificuldades na interação com os parceiros, o que se acredita dificultar o autocuidado (Pinto e col., 2007; Wainberg e col., 2008). Contudo, são limitados os conhecimentos existentes acerca dos aspectos psicossociais que envolvem a vivência da sexualidade e prevenção das IST nessa população no Brasil.

Diante desse contexto surgiram as questões que nortearam a realização desse estudo: como os homens com transtornos mentais representam possíveis riscos na vivência da sexualidade? Como fazem para se cuidar? De que forma o contexto social em que se inserem contribui ou dificulta o autocuidado frente às IST?

Assim, visando contribuir com conhecimentos que auxiliem na promoção da saúde sexual, em específico, no enfrentamento da problemática da transmissão de IST nessa população, é que essa investigação se realizou. Ela teve como objetivo analisar as percepções de homens com transtornos mentais sobre risco e autocuidado face às IST, considerando seus contextos de vida.

Trata-se de pesquisa fundamentada na teoria das representações sociais, definida por Morvan apud Giami e Veil (1997, p. 42) como:

...o ponto de vista do indivíduo em relação com um objeto ou, antes, trata-se do objeto conforme vivido e sentido pelo indivíduo, em sua complexidade, suas contradições, sua singularidade. Delimitar uma representação é desenhar o objeto que ocupa um lugar (corpo) na experiência histórica e única do indivíduo, a ponto de modificar a experiência e de orientá-la.

Giami e Veil (1997) afirma que não é necessária a utilização do termo "representações sociais" pois seria uma redundância, considerando que toda representação é social, porque se constroem nas práticas sociais e nas interações entre as pessoas. As ações são tomadas como uma dimensão presente das representações sociais, buscando-se o entendimento do complexo representação-ação e suas consequências na realidade social.

Considerando que as representações permitem aos sujeitos uma orientação diante de um objeto que é socialmente relevante, esse referencial tem sido amplamente adotado no campo da saúde. Essa teoria tem propiciado uma importante contribuição na interface social e saúde ao colocar que não há uma divisão entre o universo exterior e o interior do indivíduo. Indivíduo e objeto não são distintos. Por se tratar de um sistema simbólico organizado e estruturado pelos meios de comunicação e pelos processos psíquicos, cuja função essencial é a apreensão e o controle do mundo pelo indivíduo, permitindo-lhe compreendê-lo e interpretá-lo, esse referencial possibilita aos pesquisadores interpretar as vulnerabilidades em face dos riscos, da saúde e da doença (Giami e Veil, 1997; Moscovici, 2009).

\section{Métodos}

Tendo em vista os objetivos do estudo, optou-se pela abordagem qualitativa. Estudos dessa natureza não visam um conhecimento que possa ser universalizado como regra, mas o aprofundamento das singularidades da experiência social das pessoas.

Os sujeitos foram homens com transtornos mentais severos e persistentes, o que engloba um conjunto de diagnósticos que incluem problemas psiquiátricos mais graves, como esquizofrenia, transtorno bipolar, depressão grave e depressão com sintomas psicóticos. Essas desordens se caracterizam por apresentar sintomas crônicos e persistentes, com prejuízo nas funções. Os participantes encontravam-se em atendimento em serviços públicos de saúde mental, tendo como critério de inclusão estar fora de crise, ou seja, em condições de participar da entrevista. A seleção dos participantes, dentre todos os que atendiam a esse critério, deu-se de forma aleatória.

Para a obtenção dos dados foram realizadas entrevistas abertas e em profundidade, em salas privativas, após a assinatura do Termo de Consentimento Livre e Esclarecido. As entrevistas foram gravadas 
e depois transcritas. Foi solicitado aos entrevistados que falassem sobre suas vivências sexuais, se conheciam e o que pensavam sobre as IST, o risco de contraí-las e como se protegiam. As entrevistas foram realizadas em dois hospitais psiquiátricos de Belo Horizonte, Minas Gerais, e em dois serviços ambulatoriais de saúde mental, um situado em Betim, Minas Gerais, e outro na cidade de Carmo, Rio de Janeiro, nos quais havia maior facilidade de acesso dos pesquisadores.

Os sujeitos foram assegurados quanto ao direito de se negar a participar da pesquisa sem qualquer prejuízo ao sigilo e ao anonimato das informações. Não houve definição do número de participantes $a$ priori, sendo o critério para suspensão da coleta de novas entrevistas a saturação dos dados. Participaram do estudo 22 homens.

Os dados foram analisados com base na proposta de análise estrutural de narração (Demazière e Dubar, 1997), realizada em três etapas (Blanchet e Gotman, 1992). Primeiramente realizou-se análise minuciosa de cada entrevista, quando se buscou o sentido global do conteúdo. Posteriormente, cada objeto da fala foi numerado em sequências, logo em seguida reagrupadas por assuntos tratados. Nesse momento foi possível desvelar o conjunto das representações dos entrevistados por meio de seus julgamentos, valores, opiniões, afirmações e práticas. Por fim realizou-se análise comparativa do conjunto das entrevistas, quando se deu a categorização final dos significados encontrados, interpretados à luz da literatura.

Não houve nenhum propósito de relacionar os achados com quaisquer questões relativas ao diagnóstico clínico dos sujeitos, uma vez que se considera que, independentemente da especificidade do transtorno mental, para todos fazem-se necessárias ações de promoção de prevenção de IST.

Esse estudo foi aprovado pelos serviços de saúde participantes, pelo Comitê de Ética em Pesquisa da Universidade Federal de Minas Gerais (COEP/ UFMG), parecer nº. ETIC 125/03, e pela Comissão Nacional de Ética em Pesquisa (CONEP), parecer $n^{\circ}$. 592/2006, respeitando as Resoluções de n 196/96 e 25/97 do Conselho Nacional de Saúde.

\section{Resultados e discussão}

Os resultados analisados resultaram na elaboração de três categorias: 1) contexto social e vivências sexuais dos entrevistados; 2) percepção sobre riscos e necessidade de cuidados para a prevenção das IST; 3) percepção do próprio risco e estratégias de autocuidado adotadas para a prevenção das IST.

\section{Contexto social e vivências sexuais dos entrevis- tados}

Os participantes tinham faixa etária entre 21 e 70 anos, com média de 42 anos. Doze entrevistados estavam em atendimento ambulatorial e dez encontravam-se hospitalizados. Quanto ao nível de escolaridade, 6 eram analfabetos, 14 tinham ensino fundamental incompleto, somente 1 tinha ensino médio completo e 1, ensino superior completo. Doze relataram ter emprego e seis afirmaram nunca ter trabalhado. Os trabalhos relatados por eles foram: caminhoneiros, trabalho no campo, marceneiro e eletricista. Apenas oito relataram algum tipo de renda estável, proveniente de benefício ou aposentadoria, sendo essa renda em torno de um salário mínimo. Os demais contavam com rendas esporádicas, sendo alguns sustentados por familiares e outros dependentes de caridade alheia.

O contexto de pobreza e a baixa escolaridade do grupo pesquisado corroboram os achados do eixo quantitativo do projeto PESSOAS (Brasil, 2008), no qual foram investigadas mais de duas mil pessoas com transtornos mentais em todo o Brasil. O estudo mostrou que $70 \%$ dessa população tinham menos de oito anos de escolaridade e menos de 30\% relataram algum tipo de renda individual. Conseguir um emprego foi manifestado como o maior sonho de muitos dos entrevistados, o que afirmaram ser muito difícil de conseguir, e se acredita decorrer, inclusive, de preconceito social contra pessoas com transtornos mentais.

Observou-se no grupo baixa autoestima, o que esteve atrelado a situações de exclusão vividas, sendo pessoas que se vêm como "problemáticas", que se verifica na fala que se segue: Ninguém quer saber de mim. As pessoas acham que só causo problemas (E12, 30 anos). 
Dentre os 22 entrevistados, apenas oito relataram ter vivido relações afetivo-sexuais estáveis, o que se verificou decorrer da dificuldade em conseguir parceiras(os). Desses, seis haviam se separado. Em um caso a união era com pessoa do mesmo sexo. A instabilidade das relações foi atribuída a dificuldades na convivência conjugal; alguns disseram terem sido abandonados pelas companheiras por terem se relacionado com outra(s) parceira(s). Houve quem atribuísse o rompimento dos relacionamentos à infidelidade conjugal das parceiras e ao uso de drogas feito por eles. Um depoente relatou ter se separado pelo fato de ter descoberto que a parceira estava com aids. Um participante era viúvo. Vinte participantes encontravam-se sem parceiras(os) estáveis no momento da realização das entrevistas, tendo sido comum o relato de procura por profissionais do sexo pelas dificuldades em conseguir outras parceiras. Quinze depoentes não tinham filhos, e dentre aqueles que os tinham somente dois afirmaram manter algum contato com eles. 0 distanciamento dos filhos foi justificado por atritos na convivência, com relatos de situações de agressividade ora infringida, ora sofrida.

O uso de bebidas alcoólicas foi afirmado por sete entrevistados. 0 uso de drogas ilícitas também foi afirmado por sete participantes. 0 uso dessas substâncias foi justificado como uma forma de aliviar angústias, solidão e abandono: Eu bebo pra esquecer coisas ruins (E29, 42 anos). 0 uso de drogas foi percebido ainda como forma de propiciar inserção grupal, como relatado por um participante que afirmou sofrer muito com o preconceito por ser homossexual: A droga é uma forma de me sentir aceito em algum grupo (E5, 44 anos).

Cabe pontuar que três homens tinham histórico de encarceramento por envolvimento em assassinato, roubo e tráfico de drogas. Um depoente relatou ter sofrido tentativa de assassinato e outro se disse ameaçado de morte. Faz-se necessário citar ainda que no relato de dois entrevistados observaram-se situações de violência sexual sofrida por pessoas do mesmo sexo, o que, no entanto, não foi descrito por eles como uma situação de violência; em uma dessas situações a violência ocorreu dentro do serviço de saúde mental.

São dados que mostram que essa população tem vida sexual ativa e comportamentos sexuais de risco, o que foi encontrado em estudos realizados com esse grupo populacional também em outros países (Meade e Sikkema, 2005; Meade, 2006). Eles caracterizam um contexto social complexo, mais difícil do que o da população em geral no Brasil, o que se reflete em maiores limitações para o autocuidado e, inclusive, para a própria sobrevivência. São pessoas que encontram dificuldades para se defender de situações de abuso, tendo sido observado que muitas vezes não conhecem e não sabem como reivindicar seus direitos, dentre os quais a uma sexualidade sadia. Os achados evidenciam lacunas no cuidado integral e equitativo.

\section{Percepção sobre riscos e da necessidade de cui- dados para a prevenção das IST}

Pelas narrativas, observou-se que os entrevistados têm conhecimentos sobre as possibilidades de transmissão de "doenças" através dos relacionamentos sexuais, e consequentemente da necessidade de cuidados para a autoproteção. O principal fator despertador da necessidade de se autocuidar foi a representação da aids como uma doença "incurável, causadora de grande sofrimento e mortal": Aids é morte. Mata!, (E25, 42 anos); Pegou aids, acabou (E22, 46 anos); Aids é o fim da vida (E36, 72 anos). Verificou-se como fator motivador do autocuidado, ainda, a crença de que pessoas infectadas pelo HIV têm intenção de transmitir a "doença": Quem tem aids quer transmitir para se vingar (E19, 37 anos). As demais IST não se mostraram motivos de maior preocupação para os entrevistados, o que se verificou decorrer da crença na possibilidade de tratamento e cura: As outras têm cura, né? (E29, 42 anos). Esse menor temor pelas demais IST, no entanto, pode decorrer também do maior desconhecimento sobre esses agravos. Poucos foram os participantes que citaram nomes de IST, além da aids, e que conseguiram falar algo sobre elas. No caso daqueles que se referiram a alguma IST, constatou-se que isso se deu pelo fato de ter sido contraída ou pela proximidade com pessoas infectadas. 
Os achados vão ao encontro do que foi colocado por Douglas (1994), para quem os significados atribuídos aos riscos ${ }^{2}$ e, consequentemente, a necessidade de se autocuidar, se relacionam com a extensão das consequências e com o valor social a eles atribuídos, em seus contextos sociais. Nesse sentido, o maior temor da aids pode estar relacionado ao fato de ainda ser uma infecção muito estigmatizada na sociedade. É um sentido que difere daquele atribuído ao risco na área da saúde, que é focado na probabilidade da ocorrência de algo negativo (Calvez, 1993).

Uma motivação para o autocuidado voltada para a valorização do estado de saúde em si esteve presente na fala de uma minoria, como explicitado a seguir:

Tem que usar o preservativo, tem que usar. Comigo não acontece porque eu não tenho mais... [se referindo a ter relação sexual]. Mas tem que usar! Porque a vida da gente é a coisa mais maravilhosa que a gente tem. Porque se uma pessoa tiver o vírus, pode passar pro outro. [...] Porque eu não sei o que a senhora tem, e a senhora não sabe o que eu tenho... Se preservaréuma coisa muito boa. É tão bom quando se está com saúde! (E36, 72 anos).

A pouca valorização atribuída por esse grupo ao seu bem-estar pode decorrer de sua exclusão social e de baixa autoestima, encontradas nos resultados da presente pesquisa (Adam e Herzlich, 1994).

Houve um participante que apresentou destemor e fatalismo quanto ao risco de se infectar: Se eu pegar, posso fazer o quê? Posso fazer nada! (E12, 30 anos). Tratava-se de um entrevistado separado de sua mulher que relatou ter perdido um irmão devido à aids. Ele mostrou conhecimentos acerca da necessidade de se proteger, tendo relatado inclusive facilidade na obtenção de preservativos nas unidades básicas de saúde. Ainda assim, afirmou manter relações sexuais desprotegidas: Quem quiser que se cuide. Seu destemor foi observado como relacio- nado à falta de perspectivas de vida, tendo relatado ter sido vítima de tentativa de assassinato e estar ameaçado de morte devido ao tráfico de drogas. Esse entrevistado manifestou "satisfação" por ter sido internado em um hospital, local onde se sente "seguro". Seu relato remete a Le Breton (1991), para quem, sendo a morte o significante último, jogar com a vida e com o risco de perdê-la é jogar simbolicamente com a existência, com o objetivo de conseguir um sentido a mais que tornaria a vida plena.

Segundo Douglas (1994), na atualidade, o sentido atribuído ao risco na área da saúde encontra-se na vertente do individualismo, por tratar a morte como uma responsabilidade de cada um e o adoecimento como uma responsabilidade quase criminal, devendo cada indivíduo fazer todo o possível para se manter saudável, o que tem ocasionado sentimentos de culpa nas pessoas acometidas pelos agravos. Corrobora-se com este autor, entendendo ser esse o motivo pelo qual muitos entrevistados afirmaram fazer o uso do preservativo masculino nas relações sexuais, o que se verificou não ser verídico ao longo de seus próprios relatos. A afirmação sobre o uso do preservativo parece se dar tanto em decorrência de apresentar-se como uma pessoa responsável, o que é socialmente esperado, quanto para eximir-se da culpa atribuída pela sociedade.

\section{Percepção do próprio risco e estratégias de autocuidado adotadas para a proteção face às IST \\ 0 risco relacionado à representação sobre as(os) parceiras(os) sexuais e a seleção como forma de se autocuidar}

Mesmo reconhecendo a possibilidade de transmissão de IST nos relacionamentos sexuais, para

\footnotetext{
20 termo risco teve sua origem entre os séculos 16 e 17, vindo substituir a palavra perigo no contexto dos jogos de azar, comércio marítimo e análise matemática, referindo-se à chance de um evento acontecer. A partir do século 19, sua relação com a probabilidade/possibilidade se fortaleceu, sendo amplamente utilizado na economia. Desde então, o termo passou a ser associado também à ideia de escolha racional, com vistas à possibilidade de ganhos e perdas. Seu uso se expandiu para a epidemiologia, passando a ser empregado na abordagem de problemas coletivos, sendo fortalecida sua imagem associada a situações negativas que expressam situações ruins ou indesejáveis. Para Douglas (1994), o termo risco significa o mesmo que perigo, referindo-se a algo sujo, poluído, inaceitável, mas numa forma mais decorativa. No entanto, ele se revestiu de cientificidade, passando a ser objetivamente controlado. Trata-se, hoje, de um termo utilizado universalmente, que aqui foi tomado na sua acepção sociológica de perigo, involuntário ou buscado pelo sujeito ou coletivamente, como para Le Breton (1995).
} 
a maioria dos entrevistados a percepção sobre o próprio risco de se infectar esteve relacionada à representação sobre as(os) parceiras(os) sexuais. Para eles, parceiras(os) que oferecem risco são profissionais do sexo, "mulheres vadias" ou que vão com muitos outros parceiros, e pessoas doentes: $A$ camisinha é preciso quando for no motel ou boate. Aí tem que usar, claro (E1, 22 anos); Quando évadia não tem jeito [de não usar] (E19, 37 anos). Mulheres casadas foram vistas como parceiras sem risco, bem como mulheres novas e viúvas, o que parece decorrer da representação dessas como pessoas que se relacionaram com poucos parceiros sexuais.

Verificou-se, ainda, a percepção de uma parceira como de risco quando a mulher demanda o uso de preservativo. Ao relatar que [...] Cuidar(se) é não transar com mulher que tem doença, foi indagado ao entrevistado como ele sabia quando alguém tinha uma doença; ao que ele respondeu: $S e$ (ela quiser) usar camisinha, aí você sabe (E26, 24 anos). Nessa fala, além da explicitação de uma falta de orientação clara que o leva a um julgamento incorreto, verifica-se a ideia do uso de preservativo associado a comportamentos de risco. Essa representação pode contribuir para a resistência ao uso, inclusive, por temerem ser vistos como pessoas "de risco".

A percepção de risco visualizada apenas em determinados grupos foi encontrada em estudos realizados com os mais diversos grupos sociais (Alves, 2003; Andrade e Nóbrega-Therrien, 2005; Coelho, 2006; Oltramari, 2007). Essa representação parece decorrer do enfoque dado a alguns grupos às primeiras campanhas realizadas de prevenção da aids, como as centradas em profissionais do sexo. Esse enfoque foi dado pela constatação de maior incidência da transmissão em determinados grupos, o que, no entanto, acabou por propiciar uma sensação de isenção de risco nos demais, constituindo-se hoje um dos aspectos dificultadores para o uso do preservativo entre parceiros que não pertençam a esses grupos. A prevalência das IST é, de fato, maior em alguns grupos específicos, como de profissionais do sexo, quando comparados à população em geral. Isso, contudo, não elimina o risco existente nos demais grupos sociais, os quais têm apresentado, inclusive, as maiores taxas de crescimento da infecção pelo HIV nos últimos anos (Brasil, 2008).
Devido à construção de representações de risco apenas em parceiros de risco, o autocuidado para a prevenção das IST do grupo pesquisado se centrou em selecionar os parceiros. Não se relacionando com aqueles vistos como arriscados, o uso de preservativo não foi visto como necessário, sendo essa a principal lógica norteadora do autocuidado. Verifica-se nessa crença que a doença é reconhecida apenas quando há sinais e sintomas visíveis, não sendo vista como possível em pessoas de boa aparência, o que corrobora autores como Adam e Herzlich (1994), para os quais a doença, na sociedade, se reduz à sua realidade concreta.

Para o "processo" de seleção de parceiras(os), um dos caminhos é interrogar o outro sobre seu estado de saúde e sobre a existência de doenças: Eu que perguntava para elas se tinham doença. E elas falavam que não, que eu podia confiar (E3, 50 anos). Trata-se de estratégia que demonstra, além da confiança na idoneidade do parceiro e na veracidade da resposta recebida, não contar com a possibilidade de que o parceiro possa ter infecções que ele mesmo pode desconhecer. Em alguns relatos observou-se que eles contam com o fato de que seriam avisados por terceiros, caso se relacionasse com pessoas infectadas: Quando a pessoa tem a doença, todo mundo fica sabendo e avisa a gente (E30, 24 anos). Tal perspectiva mostra a crença de que todas as pessoas infectadas são de conhecimento público.

A estratégia de ter relações com pessoas "conhecidas" como forma de se autocuidar foi marcante nas falas:

[...] Se não for mulher que conhece, [...]. Porque eu acho assim. [...] se vocênão conhece o parceiro, você tem que prevenir, não é? Se você não conhece, com um e com outro, você não sabe. Aí então eu acho que tem que sair fora. Pode ser uma mulher bonita, se ela chegar perto de mim, eu desconfio. Eu dou mais valor a uma feia que está ali, que ninguém quer ela, mas que eu conheço, que uma mulher bonita demais. (E19, 37 anos).

No relato dos homens, constatou-se ainda uma sensação de segurança proveniente da crença de que mulher, quando não se relaciona com outros homens, não representa riscos por não se relacionar com muitos parceiros, como se observa na fala de um deles: Eu confio nela. Ela não vai com outros homens 
(E25, 42 anos). Isso também foi identificado em estudo com homens casados realizado por Silva (2002).

Para um parceiro(a) ser considerado(a) "de confiança” bastou um pouco de conversa e aparentar boa saúde:

$\varepsilon u$, sabendo que a pessoa é de confiança, não precisa usar camisinha. Só de eu ver, conversando com ela, eu sei se ela é de confiança ou não é. Quando você sente que a pessoa é honesta, não precisa usar camisinha (E1, 22 anos, solteiro).

Também o fato da parceira ser moradora do mesmo bairro já foi o suficiente para que se sentissem seguros: Essa moça mora aqui (se referindo a uma mulher do bairro). Com ela não tem perigo (E25, 42 anos). Se, no imaginário social, o que é familiar parece significar proteção, conforme revelam as análises de Giami e Veil (1997), essa associação ganha ainda maior relevância e significado em um contexto relacional marcado pela exclusão social. $\mathrm{O}$ autocuidado realizado predominantemente através da seleção de parceiros “de aparência saudável” é apontado também em estudos realizados com outros grupos sociais (Alves, 2003; Antunes e col., 2002; Oltramari, 2007).

Cabe ressaltar uma constatação deste estudo. Apesar de os homens verem as profissionais do sexo como uma categoria "de risco", elas continuaram a ser procuradas. Essa conduta mostrou-se decorrente do fato dessas mulheres serem, para muitos, a única possibilidade de realização de práticas sexuais. Contudo, mesmos nesses casos, raramente usaram preservativo nas relações, tendo prevalecido a estratégia da seleção de parceiras "sadias e confiáveis", como se observa a seguir:

Lá eu escolhia a mulher adequada, que é pra não ter problema. Eu nunca usei (preservativo). Eu escolho a pessoa certa pra mim poder ficar. [...] Exatamente porque já tive gonorréia e cancro. [...] Eu procuro a mulher adequada pra não pegar, porque eu pegueie fiquei com medo. Então, já vou na pessoa certa, pra não pegar nunca mais” (E34, 57 anos).

Nesse relato verifica-se que nem o fato de o entrevistado ter contraído IST por duas vezes fez com que o uso do preservativo fosse adotado. Ele demonstra se sentir seguro com a parceira escolhida. E relatou ter medo de contrair IST com mulheres de rua, mas não com as do cabaré, pelo fato dessas últimas serem “conhecidas" para ele, não havendo preocupação com as multiparcerias obrigatórias impostas pela profissão, sem uso de preservativo.

\section{Aspectos facilitadores e entraves ao uso do pre- servativo}

Entre os entrevistados que relataram nunca ter tido relação sexual, todos afirmaram que vão fazer uso de preservativo quando vierem a se relacionar sexualmente: Eu sei usar. Eu quero usar e vou usar (E15, 25 anos); Quando eu tiver (relação sexual) vou me proteger com camisinha (E1o, 25 anos). Entretanto, dentre estes, somente um apontou a percepção de risco presente em todas as pessoas: Todo mundo está em risco (E1o, 25 anos). Essa percepção mostrou-se relacionada à experiência da contração do HIV por um familiar, em relacionamento estável.

Alguns homens relataram não se verem em risco de contrair IST, o que foi atribuído ao fato de não mais terem relacionamento sexual e por não pretenderem tê-lo novamente. Esses depoentes se caracterizaram maiores de 50 anos, separados ou viúvos. Todos eles negaram o uso de preservativo alguma vez na vida, o que foi atribuído ao fato de não disporem desse recurso quando tiveram vida sexual ativa. Contudo, demonstraram preocupação com a percepção de risco visualizada nos filhos: Quero aprender mais sobre isso (prevenção de DST), porque penso em mim enos meus filhos, e penso nos outros também (E36, 72 anos). Esse relato enfatiza a importância da promoção da saúde sexual para todas as pessoas, independentemente de sua atividade na atualidade, uma vez que são potenciais educadores para a saúde sexual de seus filhos e também de outras pessoas.

O uso de preservativo masculino para a autoproteção foi relatado por uma minoria, sendo que a conduta foi justificada pelo fato de as parceiras serem profissionais do sexo, ressaltando-se que somente alguns dos entrevistados que se relacionaram com elas fizeram o uso. Ainda assim, constatou-se que o uso se deu principalmente por uma exigência das profissionais do sexo. Além disso, o uso de preservativo se mostrou motivado mais por ser um método anticoncepcional do que com a intenção de se autoproteger das IST: Usei para evitar dela engravidar (E38, 44 anos). 
Somente um homem afirmou ter feito uso sistemático de preservativo desde o início dos relacionamentos sexuais, tanto naquelas com profissionais do sexo quanto com as namoradas. Tratava-se de um jovem que se mostrou bastante consciente dos riscos de contrair IST. Sua conscientização vem de orientações familiares e de informações da mídia:

Eu comprava, ganhava ou arranjava. Sempre eu tive (camisinha). Usar previne. Meu pai advertia meus irmãos que existia várias doenças, que tem a aids que não tem cura. [...] não dá pra confiar em ninguém. Só se for casado, né? Às vezes até casado tem risco também, né? Porque uma pessoa pode trair a outra e ter uma doença mesmo no casamento. [...] Sempre fui informado e sempre tive noção do perigo da aids, da gonorreia, da sífilis, do cancro, tudo. Sempre vi na televisão (E2, 27 anos).

Tratou-se do único entrevistado a afirmar que não se pode confiar em ninguém, nem mesmo em parceiros de relacionamentos estáveis. Ele relatou ter tido relação sexual no hospital psiquiátrico e ter feito uso de preservativo, que conseguiu com um colega também era portador de transtorno mental, que, por sua vez, o recebera de um familiar. Ao ser indagado como faria se não tivesse conseguido o preservativo, respondeu: Não faria. Contudo, no transcurso da entrevista, foi interrogado se preferia não ter relações a se expor a riscos, caso a parceira quisesse ou aceitasse ter relação sexual desprotegida; respondeu: Aí éque tá o problema, porque a gente cai na tentação. A vulnerabilidade se confirma, pois se mostra fraco em face da possibilidade da relação sexual sem o uso de preservativo. A fragilidade se dá devido à busca de maior prazer, e o preservativo é relegado, mesmo consciente dos riscos envolvidos nessas relações. Sua fala evidencia ambiguidades existentes numa mesma pessoa, e ilustra as tensões em que a vivência da sexualidade se dá, uma vez que pode significar riscos para a saúde, mas é, ao mesmo tempo, importante fonte de prazer e também de identidade para os homens.

Para eles nem mesmo o fato de terem contraído alguma IST ou passado por situações de risco mais evidentes, como nos casos de relacionamento com mulher que, posteriormente, descobriu ter o HIV, ou de relações "por um tempo" com uma mulher não conhecedora de sua situação sorológica, mas cujo ex-marido morrera de aids, fez com que eles adotassem o uso de preservativo. Nesses casos prevaleceu a estratégia de "seleção" de parceiras pela aparência.

Somente um entrevistado relatou ter adotado o uso do preservativo nos relacionamentos sexuais estáveis, porque viveu a experiência de contração de sífilis e gonorreia com parceiros anteriores. Tratava-se do entrevistado homossexual. Porém, o uso foi interrompido ao longo da convivência conjugal:

Eu e meu companheiro fizemos teste HIV, e de ambos deu negativo. Então nós fizemos um acordo entre nós, porque a gente se ama mesmo [...]. Acordo da gente confiar um no outro. Falei então: "agora a gente pode abrir mão desse artefato [se referindo ao uso de preservativo] entre nós, com o pacto de que, se a gente for fazer isso [ter relação sexual] fora do nosso relacionamento, a gente vai se proteger". É uma estratégia que a gente vem confiando nela. Nós já tivemos oportunidades, mas a gente não concretiza o extraconjugal. No fundo, a gente acaba mandando embora. A gente se completa bem (E5, 44 anos).

Esse entrevistado é uma exceção entre todos os homens, porque tinha maior conhecimento e demonstrou mais sensibilidade com os cuidados necessários para se evitar a contração de IST, tendo acesso à informação e reflexão por ter estudos superiores na área da saúde. Porém, justificou a contração das IST por sua falta de conhecimento anterior, o que, no aprofundamento da análise, ficou claro tratar-sede falsificação da realidade, considerando as datas apresentadas por ele ao narrar os relacionamentos anteriores. 0 risco vivenciado nas relações homossexuais em tempos de desconhecimento da existência de aids foi reiterado por ele, que também disse que usar camisinha despertava desconfiança de alguma coisa no parceiro. Em estudo realizado com homens heterossexuais casados em um bairro da periferia de São Paulo, Silva (2002) constatou que o uso do preservativo no relacionamento conjugal foi identificado como uma forma de colocar em dúvida o próprio relacionamento, o que se mostra também em relações homossexuais.

Vale ressaltar que, apesar do pacto definido pelo casal não ser uma estratégia segura, observa-se ter havido diálogo acerca do autocuidado para a prevenção entre os parceiros. Essa é uma demonstração de 
avanços em relação às demais situações, nas quais o diálogo mostrou-se inexistente e até impossível. No estudo de Paiva (1996) a capacidade de negociar o autocuidado face ao risco de IST de forma mais autônoma se deu com pessoas com maior nível de escolaridade, como verificado neste estudo.

Entre os homens verificou-se, ainda, resistência ao uso do preservativo relacionada à sensação de diminuição do prazer sexual: Eu achava ruim. Porque a gente não sentia prazer. Aquele prazer. $\varepsilon$ diferente com camisinha. Eu ainda não me acostumei com a camisinha. Eu continuo achando ruim. Só que agora não tem mais jeito de transar sem camisinha, né? (E25, 42 anos). Apesar de afirmar que com a aids não tem mais jeito e de ter se definido como uma pessoa que toma cuidado com tudo, esse depoente disse ter contraído cancro pouco tempo antes da realização da entrevista, em casa de prostituição. Ele relatou: $\varepsilon u$ sabia que tinha que usar e quis transar sem camisinha. Observa-se que se expôs conscientemente ao risco de se infectar em busca de maior prazer sexual, o que foi verificado também em outros relatos. Isso demonstra que o prazer é mais valorizado que a saúde, o que traz à tona as contradições dos discursos prescritivos sobre ser saudável, nos quais se esquece que os sujeitos são seres que querem preservar suas autonomias, que buscam a liberdade e não mudam seus modos de viver somente porque alguém considerado mais conhecedor do que ele lhe disse para fazer de outra maneira. Conforme observa Le Breton (1995), pessoas são contraditórias, impulsivas às vezes, além de terem, intrinsecamente, o prazer da transgressão por querer fazer frente à norma ou para se saber vivo - transgredir é uma forma de se sentir jovem ( $\mathrm{E}_{5}, 44$ anos). A transgressão é vivida como uma forma de sentir prazer e também como uma confirmação de poder, acentua Le Breton, sobretudo em desafio à morte, das mais diversas formas, inclusive nas atividades de lazer. Em se tratando de pessoas com transtornos mentais, desprovidas de prazer e poder, a não ser o poder da própria doença, às vezes desafios e transgressões se tornam ainda mais compreensíveis.

Assim, pode-se afirmar que a vivência de situações de risco e de adoecimento, como as experiências de IST contraídas, não implica em prevenção, pois relações sexuais de forma desprotegida persistem. Há, por exemplo, o caso do entrevistado que afirmou facilidades de acesso a preservativos, recebendo-os gratuitamente, mas trocando-os por leite. Ele se referiu ao uso como um desperdício, porque acredita que a parceira é confiável.

Outro entrevistado afirmou ter preferido deixar de ter relações sexuais a se relacionar com preservativo, o que também se acredita decorrer de fatores ligados ao prazer sexual: Não gosto de usar preservativo e não vou usar (E35, 35 anos). Tratava-se de um entrevistado com histórico de prostituição com outros homens para a compra de drogas. Perguntado sobre como faria para se proteger se voltasse a ter relações sexuais, mais uma vez o autocuidado passou pela seleção de parceiras, separando-as em direitas e galinhas, mesmo se considerando um gato escaldado:

Se eu tiver (relação sexual), não vou relacionar com qualquer pessoa, não vou. Pra eu ter relação, primeiro, euvou ter que conhecer a menina, ver se ela éuma pessoa direita. Porque transar não é sinônimo de sem-vergonhice, mas galinhagem é. Se eu chegar a ter uma parceira é porque conheço há muito tempo. Sou gato escaldado (E29, 42 anos).

$\mathrm{O}$ argumento de redução do prazer sexual para o não uso de preservativo é descrito em estudos realizados com homens de diferentes grupos sociais (Alves, 2003). No estudo realizado por Gogna e Ramos (1999) queixas sobre a diminuição do prazer foram feitas inclusive por pessoas que nunca haviam feito uso do preservativo, o que mostra a existência de uma crença sobre a diminuição do prazer quando em uso de preservativo na sociedade. No entanto, o uso de preservativo altera o tato, mas não a sensibilidade, o que faz com que a manutenção do prazer seja preservada.

Nenhum entrevistado relatou ter tido resistências por parte das(os) parceiras(os) no uso do preservativo. No entanto, no eixo quantitativo do projeto PESSOAS, $16,7 \%$ dos homens relataram que a(o) parceira(o) sexual já recusou o preservativo alguma vez, o que mostra a existência desse tipo de obstáculo também para eles (Brasil, 2008).

Apesar de não expressado pelos entrevistados, imagina-se haver ainda outros motivos dificultan- 
do a adoção do uso do preservativo, como aqueles relacionados ao desempenho sexual, o que pode não ter sido relatado por vergonha. No estudo realizado por Alves (2003) encontrou-se como entrave ao uso do preservativo a satisfação em deixar o sêmen no corpo da mulher, o que se acredita poder ocorrer também com os entrevistados desta pesquisa.

Cabe pontuar que os depoentes sabem pouco sobre as IST, conhecendo-as essencialmente pelo nome. Eles afirmaram terem tido informações sobre esses agravos por meio de amigos, televisão e revistas. Somente dois entrevistados relataram ter recebido algum tipo de informação sobre esses agravos e sobre o uso de preservativo nos serviços de saúde mental, o que está corroborado pelos achados do eixo quantitativo do Projeto PESSOAS, no que se refere à avaliação dos serviços sorteados: a inexistência de atividades de prevenção, como regra generalizada (Melo e col., 2007). Nenhum entrevistado relatou a busca por unidades básicas de saúde para consultas voltadas para o controle da saúde.

É sabido que o conhecimento e o acesso a preservativos não são suficientes para a adoção de condutas de proteção contra as IST, o que está evidenciado neste estudo. Entretanto, ele é imprescindível para que o autocuidado seja possível e realizado corretamente. Ressalta-se que a maioria dos depoentes manifestou interesse em aprender mais sobre as IST, aprendizagem vista como importante e necessária, o que se mostra uma porta aberta para as ações de promoção da saúde sexual nessa população. Entre os poucos que se manifestaram negativamente quanto a participar de atividades educativas, declararam saber o suficiente sobre esses agravos, o que, entretanto, foi identificado como não sendo uma justificativa procedente.

\section{Considerações finais}

Os resultados encontrados no estudo mostram diversidades e singularidades nas significações elaboradas por homens com transtornos mentais sobre os riscos e autocuidado em saúde sexual, nas quais se visualizam ambivalências e ambiguidades que o discurso da prevenção das IST apresenta para eles. O risco se mostrou algo que confronta o prazer e a conjugalidade, aspectos já tão difíceis para essas pessoas, e com a própria identidade. Sua projeção para algo que está distante contrapõe-se à racionalidade esperada para o discurso da prevenção, tornando-se um fator de vulnerabilidade.

Por se tratar de um grupo que se caracteriza por baixa renda e escolaridade, exposto à violência diária e à falta de perspectivas de uma vida melhor, o risco de infecção se mostrou dimensionado de forma comparativa e hierarquizada, em relação a outros tantos que são vivenciados por essa população, sendo visto como menos importante em face de outros mais evidentes, como o de sobrevivência.

As dimensões culturais aqui apresentadas permitem compreender os altos índices de contaminação nesse grupo e sinalizam a necessidade de avançar nas abordagens em educação para a saúde sexual dessas pessoas, considerando as subjetividades e os aspectos psicossociais envolvidos nesse processo. É preciso trabalhar no sentido de reverter concepções sedimentadas que se mostram desfavoráveis ao uso do preservativo. É preciso fornecer condições para que essas pessoas desenvolvam autonomia para o autocuidado. É fundamental combater o preconceito e oferecer-lhes apoio e respeito para que o autocuidado para a vida faça sentido.

\section{Referências}

ADAM, P.; HERZLICH, C. Sociologie de la maladie et de la médicine. Paris: Nathan, 1994.

ALVES, M. F. P. Sexualidade e prevenção de DST/ AIDS: representações sociais de homens rurais de um município da zona da mata pernambucana, Brasil. Cadernos de Saúde Pública, Rio de Janeiro, v. 19, p. S429-S439, abr. 2003. Suplemento 2.

ANDRADE, L. S.; NÓBREGA-THERRIEN, S. M. A sexualidade masculina e a vulnerabilidade ao HIV/Aids. DST- Jornal Brasileiro de Doenças Sexualmente Transmissíveis, Niterói, v. 17, n. 2, p. 121-126, 2005 .

ANTUNES, M. C. et al. Diferenças na prevenção da Aids entre homens e mulheres jovens de escolas públicas em São Paulo. Revista de Saúde Pública, São Paulo, v. 36, n. 4, p. 88-95, 2002. 
AYRES, J. R. C. M. et al. Vulnerabilidade e prevenção em tempos de Aids. In: BARBOSA, R. M.; PARKER, R. (Org.). Sexualidades pelo avesso: direitos, identidades e poder. Rio de Janeiro: UERJ, IMS; São Paulo: Ed. 34, 1999. p. 49-72.

BLANCHET, A.; GOTMAN, A. L'enquête et ses méthodes: l'entretien. Paris: Nathan, 1992.

BRASIL. Ministério da Saúde. Secretaria de Vigilância em Saúde. Programa Nacional de DST e Aids. Prevenção e atenção às IST/AIDS na saúde mental no Brasil: análises, desafios e perspectivas. Brasília, DF, 2008.

BRITO, P. F.; OLIVEIRA, C. C. A sexualidade negada do doente mental: percepções da sexualidade do portador de doença mental por profissionais de saúde. Ciência e Cognição, Rio de Janeiro, v. 14, n. 1, p. 246-254, 2009.

CALVEZ, M. L'analyse culturelle du risque. In: TURRSZ, A. et al. (Ed.). Adolescence et risque. Paris: Syros, 1993. p. 75-87.

COELHO, A. B. Representações sociais de homens infectados pelo HIV acerca da aids. 2006.

Dissertação (Mestrado em Enfermagem) - Escola de Enfermagem da Universidade Federal de Minas Gerais, Belo Horizonte, 2006.

DEMAZIÈRE, D.; DUBAR, C. Analyser les entretiens biographiques: l'exemple de récits dinsertions. Paris: Nathan, 1997.

DOUGLAS, M. Risk and blame: essays in cultural theory. London: Routledge, 1994.

GIAMI, A.; VEIL, C. Enfermeiras frente à AIDS: representações, condutas, permanência e mudanças. Canoas: ULBRA, 1997.

GOGNA, M.; RAMOS, S. Crenças leigas, estereótipos de gênero e prevenção de DSTs. In: BARBOSA, R. M.; PARKER, R. (Org.). Sexualidades pelo avesso: direitos, identidades e poder. Rio de Janeiro: UERJ, IMS; São Paulo: Ed. 34, 1999. p. 229-248.

GUIMARÃES, M. D. C. et al. Prevalence of HIV, syphilis, hepatitis $\mathrm{B}$ and $\mathrm{C}$ among adults with mental illness: a multicenter study in Brazil. Revista Brasileira de Psiquiatria, São Paulo, v. 31, n. 1, p. 43-47, 2009.
LE BRETON, D. Passions du risque. Paris: Métallié, 1991.

LE BRETON, D. La sociologie du risque. Paris: PUF, 1995 .

MANN, J.; TARANTOLLA, D. J. M.; NETTER, T. W. (Ed.). Aids in the world. Cambridge: Harvard University, 1992.

MEADE, C.; SIKKEMA, K. J. HIV risk behavior among adults with severe mental illness: a systematic review. Clinical Psychology Review, New Haven, v. 25, p. 433-457, June 2005.

MEADE, C. S. Sexual risk behavior among persons dually diagnosed with severe mental illness and substance use disorder. Journal of Substance Abuse Treatment, New Haven, v. 30, p. 147-157, Mar. 2006.

MELO, A. P. S. et al. Avaliação de serviços de saúde mental: assistência e prevenção às doenças sexualmente transmissíveis no contexto do Projeto PESSOAS. Revista Médica de Minas Gerais, Belo Horizonte, v. 17, p. S240-S248, dez. 2007. Suplemento 4 .

MOSCOVICI, S. Representações sociais: investigações em psicologia social. 6. ed. Petrópolis: Vozes, 2009.

OLTRAMARI, L. C. Representações sociais da aids, relações conjugais e confiança. 2007. Tese (Doutorado em Ciências Humanas) - Centro de Filosofia e Ciências Humanas da Universidade Federal de Santa Catarina, Florianópolis, 2007.

PAIVA, V. Sexualidades adolescentes: escolaridade, gênero e o sujeito sexual. In: PARKER, R.; BARBOSA, R. M. (Org.). Sexualidades brasileiras. Rio de Janeiro: Relume Dumará, 1996. p. 213-235.

PINTO, D. S. et al. Sexuality, vulnerability to HIV, and mental health: an ethnographic study of psychiatric institutions. Cadernos de Saúde Pública, Rio de Janeiro, v. 23, p. 2224-2233, set. 2007.

SILVA, C. G. M. O significado de fidelidade e as estratégias para a prevenção da Aids entre homens casados. Revista de Saúde Pública, São Paulo, v. 36, p. 40-49, abr. 2002. Suplemento 4. 
WAINBERG, M. L. et al. HIV risk behaviors among patients with severe mental illness in Rio de Janeiro, Brazil. World Psychiatry, Genève, v. 7, n. 3, p. 166-172, 2008. 